\title{
The prevalence and distribution of the variants of Gantzer's muscle: a meta-analysis of cadaveric studies
}

\author{
Adil Asghar ${ }^{1}$, Rakesh Kumar Jha ${ }^{1}$, Apurba Patra ${ }^{2}$, Binita Chaudhary ${ }^{1}$, Brijendra Singh ${ }^{3}$ \\ ${ }^{1}$ Department of Anatomy, All India Institute of Medical Sciences Patna, Patna, ${ }^{2}$ Department of Anatomy, All India Institute of Medical Sciences \\ Bathinda, Bathinda, ${ }^{3}$ Department of Anatomy, All India Institute of Medical Sciences Rishikesh, Rishikesh, India
}

\begin{abstract}
The Gantzer's muscle is often present in the flexor compartment of the forearm. It lies underneath flexor digitorum superficialis and compresses the anterior interosseous nerve. Furthermore, this muscle frequently bestows an accessory muscle of flexor pollicis longus or flexor digitorum profundus, or sometimes together. The current meta-analysis aims to compute the prevalence of subtypes of Gantzer's muscle. Major electronic databases (PubMed, Scopus, Google Scholar, etc.) were searched for title and abstract. After removing the duplicate citations, the titles/abstracts were shortlisted with the help of inclusion and exclusion criteria. The shortlisted titles/abstracts were downloaded or collected from the library. The data of all subtypes of Gantzer's muscle were pooled from shortlisted published manuscripts for meta-analysis. The pooled estimate of other anatomical characteristics was also observed. A total of 59 cadaveric studies of sample size 5,903 were evaluated for pooled prevalence of flexor pollicis longus (accessory head). Similarly, the authors evaluated 14 studies of 1,627 upper limbs for flexor digitorum profundus (accessory head). The unit of analysis was per 100 upper limbs. The Pooled prevalence of accessory muscle of flexor pollicis longus and flexor digitorum profundus were 48\% (95\% CI, 44\%-52\%) and 17\% (95\% CI, $13 \%-21 \%)$, respectively. The Gantzer's muscle is present in 2/3rd of the upper limbs. Accessory head of flexor pollicis longus is almost three times more common than the accessory head of flexor digitorum profundus. A classification of Gantzer's muscle is needed to reduce the ignorance of these variants.
\end{abstract}

Key words: Forearm, Prevalence, Hand, Skeletal muscle, Cadaver

Received July 9, 2021; Revised September 7, 2021; Accepted September 17, 2021

\section{Introduction}

Gantzer's muscle refers to a group of accessory muscles of the flexor compartment of the forearm. It descends beneath with flexor digitorum superficialis (FDS) up to mid-forearm. It takes origin from at the medial epicondyle of humerus

\section{Corresponding author:}

Binita Chaudhary (iD

Department of Anatomy, All India Institute of Medical Sciences Patna, Phulwari Sharif, Patna, Bihar 801507, India

E-mail: binitachaudhary18@gmail.com
(ME) (common flexor origin) or coronoid process of the ulna or fascial sheath of FDS or pronator teres. It inserts onto the deep flexors, i.e., flexor pollicis longus (FPL) and flexor digitorum profundus (FDP) [1]. This muscle was first reported by Albinus in the 18th century and described by Gantzer [2], a German anatomist, in 1813. Based on initial observations, the authors identified two main variants of Ganzter's muscle, i.e., accessory head of FPL (ahFPL) and accessory head of FDP (ahFDP) [3]. Underneath the FDS, Gantzer's muscle follows an oblique path from the medial to the lateral aspect of the forearm before joining the FPL [4]. Furthermore, the Gantzer's muscle can contribute to the FDP muscle through a second tendon. The presence of ahFPL and ahFDP could

\section{Copyright ( 9 2022. Anatomy \& Cell Biology}

This is an Open Access article distributed under the terms of the Creative Commons Attribution Non-Commercial License (http://creativecommons.org/licenses/by-nc/4.0/) which permits unrestricted non-commercial use, distribution, and reproduction in any medium, provided the original work is properly cited. 
be explained by the embryological events of the common flexor muscle mass, which splits into two strata: deep and superficial during differentiation [1]. The FPL, FDP, and pronator quadratus muscles are all derived from the deep layer. Gantzer's muscle is the product of an imperfect cleavage of the deep layer [4]. The human gained the FPL during its evolution. The introduction of FPL into the flexor compartment allowed the thumb to move independently in three different planes [5]. A detailed meta-analysis was conducted by Roy et al. (2015) [6] on the ahFPL variant of Gantzer's muscle. The authors did not include ahFDP. There was at least a dozen of the manuscript which dealt with ahFDP. So, the pooled prevalence of Gantzer's muscle in the previous meta-analysis may be considered inaccurate. Finding such deficiency in the previous meta-analysis forced us to conduct the current study to elucidate the pooled estimate of both variants (ahFPL and ahFDP) and unfold the more comprehensive picture. This research aimed to determine the pooled prevalence of these accessory muscles in various populations and their morphometry and relation to the anterior interosseous nerve (AIN). It will be helpful in clinical diagnosis and surgical approaches to the forearm.

\section{Materials and Methods}

\section{Search strategy}

The authors have conducted a thorough search of the electronic databases PubMed, Google Scholar, Scopus, ScienceDirect, and EMBASE to find papers suitable for inclusion in the meta-analysis. Gantzer's muscle or accessory head of FPL or ahFPL and accessory head of FDP or ahFDP were among the keywords used in the quest. There were no time or language limitations. We thoroughly reviewed relevant studies or publications to identify potentially qualified articles for the meta-analysis.

\section{Inclusion and exclusion criteria}

Studies with extractable data on the occurrence of Gantzer's muscle in the upper limbs were deemed suitable for inclusion in the meta-analysis. The meta-analysis excluded publications that were case reports, letters to the editor, or conference abstracts, original articles which had insufficient data. During the eligibility appraisal, any disputes among the reviewers are resolved by consensus among all reviewers. The appraisal of quality of each study was conducted with the help of the Anatomy Quality Assessment tool [7].

\section{Data extraction}

The authors have collected information on the prevalence of ahFPL or ahFDP, origin, insertion, nerve supply, laterality, relation with nerves of the forearm, and morphological variation from included studies. In addition, we contacted the manuscript authors for more information via email if necessary information was missing.

\section{Statistical analysis}

Statistical analysis was performed by $\mathrm{R}$ statistical package 4.2.0 (R Foundation for Statistical Computing, Vienna, Austria). The Higgin's I ${ }^{2}$ test was used to determine study heterogeneity. A fixed-effects model was used if heterogeneity (Higgin's $\mathrm{I}^{2}$ statistics) was less than $50 \%$. A randomeffects model was used if the heterogeneity ( $\mathrm{I}^{2}$ statistics) was greater than $50 \%$. To investigate the causes of heterogeneity, subgroup analysis, sensitivity, and cumulative analysis were used when needed. The unit of analysis was per 100 upper limbs examined.

\section{Results}

\section{Characteristics of included studies}

Fifty-eight studies in the current review have been undertaken to explore the prevalence of Gantzer's muscle (Fig. 1) [3, $4,8-55]$. These studies examined 5,903 upper limbs for ahFPL variant (Table 1). Only 14 studies have been explored for the prevalence of ahFDP, including the data of 1,627 limbs (Table 1) [3, 8-14, 54]. A total of 5,903 limbs were included in the meta-analysis, which has data from 1868 to 2021. The data of Wagenseil (1936) [54] was bifurcated according to the population because they estimated the prevalence of Gantzer's muscle in Mongoloid and European populations. These data were collected from June 2020 to February 2021. The study population was predominantly adult cadavers, except for one study, i.e., Kara et al. (2012) [32]. The majority of manuscripts included in the review had wide geographical distribution, and it included data from all subcontinents except Australia.

\section{Prevalence}

The pooled prevalence of Gantzer's muscle (ahFPL and ahFDP) was found to be $65 \%$ (95\% confidece interval [CI], $57 \%-73 \%$ ) in 5,903 upper limbs. Fifty-eight cadaveric studies ( $\mathrm{n}=5,903$ upper limbs) reported the pooled prevalence of only ahFPL to be $48 \%$ (95\% CI, $44 \%-52 \%$ ) (Fig. 2). The 


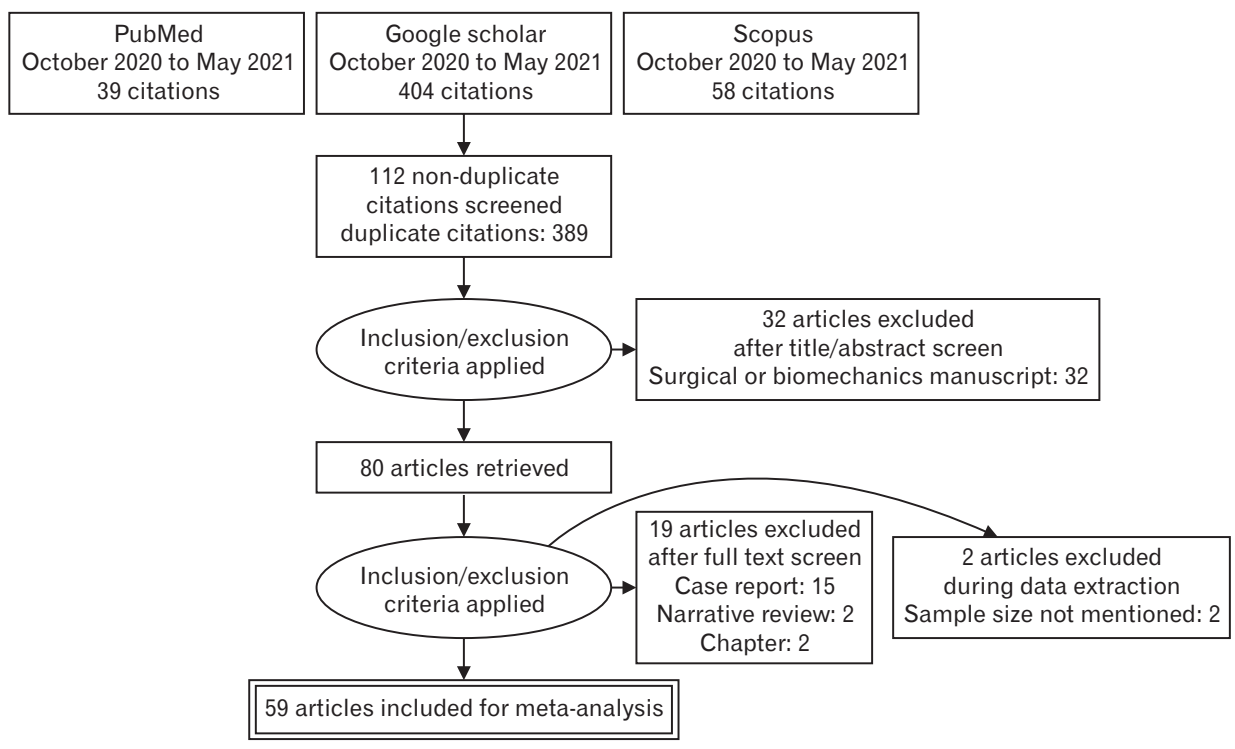

Fig. 1. Preferred Reporting Items for Systematic Reviews and Meta-Analyses flow diagram of search strategy for Gantzer's muscle. sensitivity analysis was conducted to capture the fluctuation in the prevalence after excluding each study. The range of variability of prevalence was $1 \%(47 \%-48 \%)$. The cumulative analysis was executed to examine the maximum variations in the prevalence estimates by adding each study.

The pooled estimate of the only ahFDP in 1,627 limbs from 14 studies was $17 \%$ (95\% CI, 13\%-21\%) (Fig. 3). The variability of the pooled estimate was $2 \%$ in sensitivity analysis and $8 \%$ in cumulative analysis. Thus, the heterogeneity of the estimate was $74.3 \%$.

\section{Ethnic and geographical distribution}

African studies have demonstrated the highest prevalence, $73 \%$ (95\% CI, 53\%-87\%) of ahFPL in 157 limbs with nil heterogeneity. The Mongoloid population 56\%, (95\% CI, 47\%-65\%) in 2,532 limbs and North American population $51 \%$, (95\% CI, 40\%-61\%) in 589 limbs have similar prevalence. South American studies, including 521 limbs, have a prevalence of $44 \%$ (95\% CI, 29\%-60\%). The Caucasian population (Asian 41\% in 1,447 limbs and European 39 \% in 657 limbs) has a lower prevalence of ahFPL than the ethnicities mentioned earlier. No studies were reported from the Australian population. The heterogeneity among studies of other ethnic groups varied from $76 \%$ to $94 \%$.

The prevalence of ahFDP was $24 \%$ (95\% CI, 22\%-27\%) in Mongoloid population without any heterogeneity of estimate. The same prevalence in African, Caucasian of Asian and European origin were 9\% (95\% CI, 3\%-23\%), 17\% (95\% CI, $11 \%-26 \%)$ and $11 \%(95 \%$ CI, $7 \%-18 \%)$, respectively. The prevalence in North and South American populations were based on only a single study, and they were $3 \%$ (95\% CI, $0.7 \%-10 \%)$ and $3 \%(95 \%$ CI, $0.41 \%-18 \%)$, respectively. Most of the estimates have wider confidence intervals due to the low sample size.

\section{Laterality and sex distribution}

The laterality of ahFPL was examined in 1,275 limbs (Table 2). The occurrence of ahFPL was more frequent in right side (49\%) (95\% CI, 46\%-53\%) than left side (45\%) (95\% CI, $42 \%-49 \%)$ with rate difference of $5 \%$ (95\% CI, $0.2 \%-11 \%, P=0.043$ ). Almost, similar occurrences of ahFDP were in right and left upper limbs, i.e., $9 \%$ (95\% CI, 5\%-14\%) and $10 \%$ (95\% CI, 6\%-15\%), respectively. The unilateral occurrence of ahFDP was $8 \%$, and bilateral occurrence was slightly higher, i.e., $10 \%$. The data on sex distribution was inadequate. The prevalence of ahFPL was $38 \%$ in males and $13 \%$ in females in 402 limbs which would be misleading. The distribution of ahFDP in males and females was $12 \%$ and $23 \%$, respectively. So, females have a double prevalence rate of ahFDP.

\section{Anatomical distribution}

The origin of ahFPL was evaluated in 1,283 limbs (Table 2). The commonest site of its origin was ME in $37 \%$ ( $95 \% \mathrm{CI}$, $35 \%-40 \%$ ) followed by coronoid process of ulna (CP) in $24 \%$ (95\% CI, 22\%-26\%), and muscle sheath of FDS in 15\% (95\% CI, 13\%-17\%). The dual origin from $\mathrm{ME}$ and $\mathrm{CP}$ has been observed in $8 \%$ (95\% CI, 7\%-10\%). Antebrachial fascia also 
Table 1. Study characteristics of Gantzer's muscle

\begin{tabular}{|c|c|c|c|c|c|c|}
\hline Reference & Year & Prevalence (\%), & ) $95 \%$ confidence interval & $\begin{array}{l}\text { ahFPL/ } \\
\text { ahFDP }\end{array}$ & No. and ethnicity of sample & Risk of bias \\
\hline Adachi $[53]^{\text {a) }}$ & 1910 & 63 & $54-70$ & 84 & 134 Asian Mongoloid & Unclear \\
\hline Afroze et al. [18] & 2020 & 24 & $14-38$ & 12 & 50 Asian Caucasian & High \\
\hline al-Qattan [15] & 1996 & 52 & $33-70$ & 13 & 25 Asian Caucasian & Low \\
\hline Bagoji et al. [16] & 2017 & 29 & $19-42$ & 17 & 58 Asian Caucasian & Moderate \\
\hline Bajpe et al. [17] & 2015 & 24 & $14-38$ & 12 & 50 Asian Caucasian & High \\
\hline Ballesteros et al. [19] & 2019 & 32 & $24-42$ & 34 & 106 South American & Low \\
\hline Bando [53] $]^{\text {a) }}$ & 1956 & 64 & $59-69$ & 217 & 340 Asian Mongoloid & Unclear \\
\hline Bangarayya et al. [20] & 2018 & 40 & $24-58$ & 12 & 30 Asian Caucasian & Moderate \\
\hline Bilecenoglu et al. [21] & 2005 & 20 & $9-38$ & 6 & 30 Asian Caucasian & Low \\
\hline Burute and Vatsalaswamy [22] & 2017 & 36 & $29-44$ & 56 & 156 Asian Caucasian & High \\
\hline Caetano et al. [23] & 2015 & 68 & $57-77$ & 54 & 80 South American & Low \\
\hline Chakravarthi et al. [24] & 2014 & 72 & $59-83$ & 39 & 54 Asian Caucasian & Moderate \\
\hline Dubois de Monto-Marin et al. [55] & 2021 & 11 & $4-26$ & 4 & 36 European Caucasian & Moderate \\
\hline Dellon and Mackinnon [25] & 1987 & 33 & $20-48$ & 14 & 43 North American & Low \\
\hline Desai et al. [26] & 2017 & 58 & $46-70$ & 35 & 60 Asian Caucasian & High \\
\hline Dolderer et al. [27] & 2011 & 26 & $11-50$ & 5 & 19 European Caucasian & Low \\
\hline Dykes and Anson [28] & 1944 & 53 & $45-61$ & 80 & 150 North American & Moderate \\
\hline El Domiaty et al. [8] & 2008 & 62 & $47-75$ & 26 & 42 African & Low \\
\hline Gunnal et al. [29] & 2013 & 51 & $44-58$ & 92 & 180 Asian Caucasian & Moderate \\
\hline Hemmady et al. [30] & 1993 & 67 & $53-78$ & 36 & 54 Asian Caucasian & Low \\
\hline Herrold et al. [31] & 2020 & 55 & $49-60$ & 148 & 271 South American & High \\
\hline Inoue $[53]^{\mathrm{a})}$ & 1934 & 71 & $61-79$ & 71 & 100 Asian Mongoloid & Unclear \\
\hline Jones et al. [3] & 1997 & 45 & $34-56$ & 36 & 80 European Caucasian & Low \\
\hline Kara et al. [32] (adult) & 2012 & 38 & $26-52$ & 20 & 52 Asian Caucasian & Low \\
\hline Kara et al. [32] (fetal) & 2012 & 32 & $23-43$ & 29 & 90 Asian Caucasian & Low \\
\hline Khade et al. [33] & 2020 & 53 & $36-70$ & 16 & 30 Asian Caucasian & Moderate \\
\hline Kida [34] & 1988 & 62 & $54-70$ & 82 & 132 Asian Mongoloid & Low \\
\hline Kudo and Obata [53] & 1957 & 55 & $48-61$ & 118 & 216 Asian Mongoloid & Low \\
\hline Kumari et al. [35] & 2017 & 42 & $29-56$ & 20 & 48 Asian Caucasian & Moderate \\
\hline Le Double and Berry [36] & 1897 & 33 & $28-39$ & 100 & 300 European Caucasian & Moderate \\
\hline Loth $[53]^{\text {a) }}$ & 1912 & 89 & $78-95$ & 50 & 56 African & Low \\
\hline Mahakkanukrauh et al. [37] & 2004 & 62 & $56-68$ & 149 & 240 Asian Mongoloid & Moderate \\
\hline Malhotra et al. [38] & 1982 & 54 & $48-60$ & 130 & 240 North American & Moderate \\
\hline Mangini [10] & 1960 & 74 & $63-82$ & 56 & 76 North American & Low \\
\hline Matsunaga et al. [39] & 2000 & 35 & $27-43$ & 50 & 144 Asian Mongoloid & Low \\
\hline Mohammed [9] & 2018 & 64 & $52-76$ & 38 & 59 African & Low \\
\hline Mori [41] & 1964 & 50 & $43-57$ & 103 & 205 Asian Mongoloid & Low \\
\hline Mustafa et al. [40] & 2016 & 45 & $25-66$ & 9 & 20 Asian Caucasian & Moderate \\
\hline Oh et al. [51] & 2000 & 67 & $55-77$ & 48 & 72 Asian Mongoloid & Moderate \\
\hline Oliveira et al. [11] & 2021 & 50 & $34-66$ & 17 & 34 South American & Low \\
\hline Pai et al. [12] & 2008 & 46 & $38-55$ & 58 & 126 Asian Caucasian & Low \\
\hline Philip and Dakshayani [13] & 2018 & 22 & $13-36$ & 11 & 50 Asian Caucasian & Moderate \\
\hline Ravi Prasanna et al. [42] & 2019 & 36 & $24-50$ & 18 & 50 Asian Caucasian & High \\
\hline Riveros et al. [43] & 2015 & 10 & $3-27$ & 3 & 30 South American & Moderate \\
\hline Sano $[53]^{a)}$ & 1931 & 70 & $38-90$ & 7 & 10 Asian Mongoloid & Unclear \\
\hline Sato [44] & 1969 & 25 & $22-29$ & 151 & 604 Asian Mongoloid & Moderate \\
\hline Sekizawa $[53]^{\text {a) }}$ & 1960 & 54 & $43-64$ & 45 & 84 Asian Mongoloid & Unclear \\
\hline Sharma et al. [45] & 2008 & 40 & $28-53$ & 24 & 60 Asian Caucasian & Moderate \\
\hline Shayo et al. [46] & 2015 & 42 & $30-54$ & 26 & 62 Asian Caucasian & Low \\
\hline Shirali et al. [47] & 1998 & 55 & $42-67$ & 33 & 60 North American & Moderate \\
\hline Tamang et al. [48] & 2013 & 25 & $16-37$ & 15 & 60 Asian Caucasian & High \\
\hline Tomizawa [53] & 1986 & 54 & $35-73$ & 13 & 24 Asian Mongoloid & Moderate \\
\hline Tubbs et al. [49] & 2006 & 20 & $8-43$ & 4 & 20 North American & Low \\
\hline Uyaroglu et al. [50] & 2006 & 52 & $39-65$ & 27 & 52 Asian Caucasian & Moderate \\
\hline Wagenseil [54] & 1936 & 73 & $65-79$ & 103 & 142 Asian Mongoloid & Moderate \\
\hline Wagenseil [54] & 1936 & 55 & $47-62$ & 82 & 150 European Caucasian & Moderate \\
\hline
\end{tabular}


Table 1. Continued

\begin{tabular}{|c|c|c|c|c|c|c|}
\hline Reference & Year & Prevalence (\%) & $95 \%$ confidence interval & $\begin{array}{l}\text { ahFPL/ } \\
\text { ahFDP }\end{array}$ & No. and ethnicity of sample & Risk of bias \\
\hline Wood [14] & 1868 & 61 & $49-72$ & 44 & 72 European Caucasian & Low \\
\hline Yang et al. [4] & 2017 & 48 & $37-59$ & 35 & 73 Asian Mongoloid & Moderate \\
\hline Yu et al. [52] & 2018 & 58 & $31-82$ & 7 & 12 Asian Mongoloid & Moderate \\
\hline Pooled weighted prevalence & & 48 & $44-52$ & 2,844 & 5,903 random effect model & \\
\hline Bando $[53]^{\text {a) }}$ & 1956 & 25 & $21-30$ & $86^{\mathrm{b})}$ & 340 Asian Mongoloid & Moderate \\
\hline El Domiaty et al. [8] & 2008 & 14 & $7-28$ & $6^{b)}$ & 42 African & Unclear \\
\hline Inoue $[53]^{\text {a) }}$ & 1934 & 29 & $21-39$ & $29^{\mathrm{b})}$ & 100 Asian Mongoloid & Unclear \\
\hline Jones et al. [3] & 1997 & 18 & $11-27$ & $14^{\mathrm{b})}$ & 80 European Caucasian & Low \\
\hline Kudo and Obata $[53]^{\mathrm{a})}$ & 1957 & 20 & $16-26$ & $44^{\mathrm{b})}$ & 216 Asian Mongoloid & Low \\
\hline Mohammed [9] & 2018 & 5 & $2-15$ & $3^{b)}$ & 59 African & Low \\
\hline Mangini $[10]$ & 1960 & 3 & $1-10$ & $2^{\mathrm{b})}$ & 76 North American & Low \\
\hline Oliveira et al. [11] & 2021 & 3 & $0-18$ & $1^{\mathrm{b})}$ & 34 South American & low \\
\hline Pai et al. [12] & 2008 & 14 & $9-22$ & $18^{\mathrm{b})}$ & 126 Asian Caucasians & Low \\
\hline Philip and Dakshayani [13] & 2018 & 22 & $13-36$ & $11^{\mathrm{b})}$ & 50 Asian Caucasians & Moderate \\
\hline Sano $[53]^{a)}$ & 1930 & 23 & $14-36$ & $13^{\mathrm{b})}$ & 56 Asian Mongoloid & Unclear \\
\hline Sekizawa $[53]^{\mathrm{a})}$ & 1960 & 21 & $14-31$ & $18^{\mathrm{b})}$ & 84 Asian Mongoloid & Unclear \\
\hline Wagenseil [54] & 1936 & 26 & $20-34$ & $37^{\mathrm{b})}$ & 142 Asian Mongoloid & Moderate \\
\hline Wagenseil [54] & 1936 & 10 & $6-16$ & $15^{\mathrm{b})}$ & 150 European Caucasian & Moderate \\
\hline Wood [14] & 1868 & 7 & $3-16$ & $5^{\mathrm{b})}$ & 72 European Caucasian & Low \\
\hline Pooled weighted prevalence & & 17 & $13-21$ & $302^{\mathrm{b})}$ & 1,627 random effect model & \\
\hline
\end{tabular}

ahFPL, accessory head of flexor pollicis longus; ahFDP, accessory head of flexor digitorum profundus. ${ }^{\text {a) }}$ Secondary reference was used because the data collected from secondary reference due to inaccessibility of original manuscript. ${ }^{\text {b) }}$ ahFDP.

gave origin to ahFPL in $4 \%$ (95\% CI, 3\%-5\%). The fascial sheath of FDS was the predominant site of origin for ahFDP, which was $74 \%$ (95\% CI, 65\%-82\%). The origin ahFDP from $\mathrm{ME}, \mathrm{CP}$, and pronator teres were 15\% (95\% CI, 9\%-23\%), 6\% (95\% CI, 3\%-13\%) and 4\% (95\% CI, 2\%-10\%), respectively in 214 samples.

Gantzer's muscle was inserted either in the muscle belly or tendon of FPL and FDP. The insertion of ahFPL was examined in 345 limbs (Table 3). The ahFPL was inserted in the muscle belly of FPL in $1 / 2$ nd to $2 / 3$ rd of the sample, and remaining samples were inserted on the tendinous part of FPL. The extent of ahFPL in the upper $1 / 3$ rd of the forearm was observed in $71 \%$ of the sample, followed by $23 \%$ in the middle $1 / 3$ rd and the remaining $6 \%$ extended up to the lower $1 / 3$ rd of the forearm. The insertion of ahFDP was predominantly on the tendon of the index finger, i.e., $47 \%$ (95\% CI, $37 \%-57 \%$ ), followed by the tendon of middle finger, i.e., $20 \%$ (95\% CI, 13\%-29\%) (Table 3).

The innervation of ahFPL was examined in 1,237 limbs (Table 2). AIN was the predominant supply of ahFPL in $2 / 3 \mathrm{rd}$ of samples (95\% CI, 64.1\%-69.3\%). The median nerve supplied ahFPL in 1/3rd samples (95\% CI, 30.6\%-35.9\%). Ulnar nerve innervated it in $0.1 \%$ samples (95\% CI, 0\%-4\%). The innervation of ahFDP was AIN in $55.6 \%$ and medial nerve $(\mathrm{MN})$ in $44.4 \%$ (Table 1).

\section{Morphological distribution}

The morphology of ahFPL was examined in a sample of 655 limbs (Table 2). The fusiform shape was the predominant shape of muscle which was observed in almost 3/4th of samples. The length of ahFPL varied from 6.9 to $12 \mathrm{~cm}$, and width varied from 0.3 to $0.7 \mathrm{~cm}$. The adequate data was unavailable to estimate the morphological distribution of ahFDP. However, the Fusiform shape was predominant in ahFDP.

\section{Risk of bias}

Most of the studies did not provide adequate information about sex distribution. The studies may have a high risk of bias (ROB) because the authors did not report adequate anatomical and morphological details [16, 17, 20, 25, 30, 41, 47]. The studies with a higher $\mathrm{ROB}$ reported less prevalence of ahFPL, i.e., 37\% (95\% CI, 27\%-48\%) than moderate and low ROB studies, i.e., $47 \%$ and 52\%. The prevalence of ahFDP was similar in both moderate and low risk. None of the studies was categorized into a high ROB for ahFDP.

\section{Publication bias}

The funnel plot of the current meta-analysis was symmetrical. Egger's linear regression test for publication bias was conducted, refuting the possibility of publication bias 


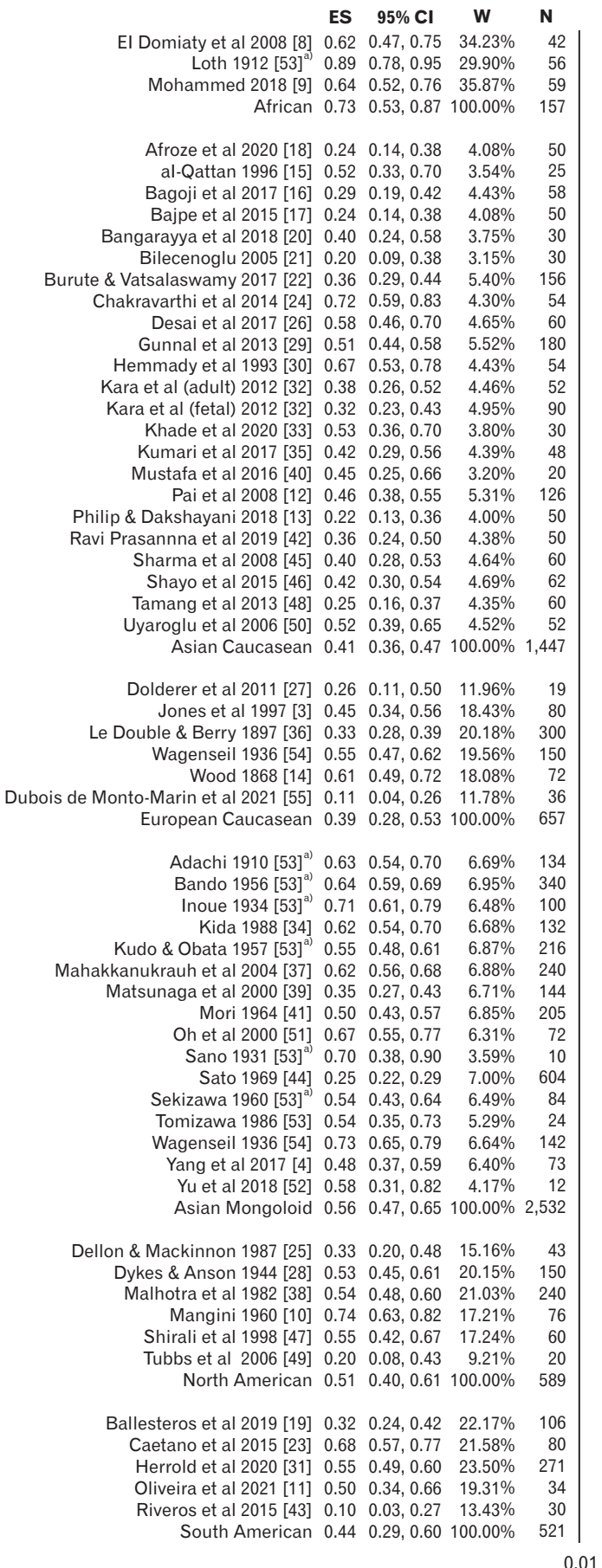

$(P$-value $=0.858)$. Trim and fill analysis was undertaken to estimate pooled prevalence. The observed pooled prevalence was similar to the estimated pooled prevalence.

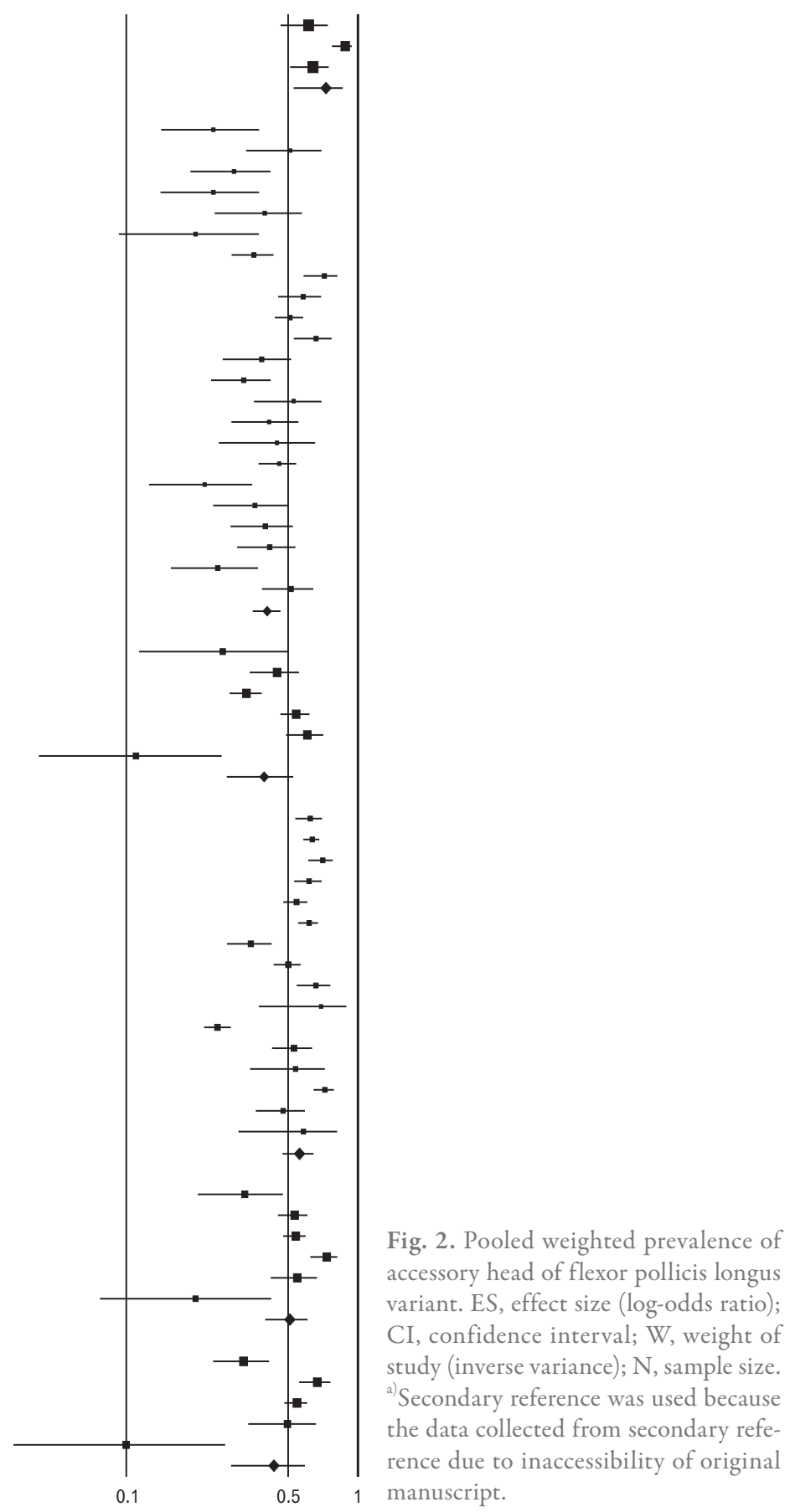

\section{Discussion}

\section{Summary of findings}

In the current meta-analysis, the prevalence of Gantzer's muscle was $65 \%$ in 5,903 upper limbs, which is inconsistent with the results of the prior meta-analysis. The pooled prevalences of ahFPL and ahFDP variants were $48 \%$ and $17 \%$, re- 


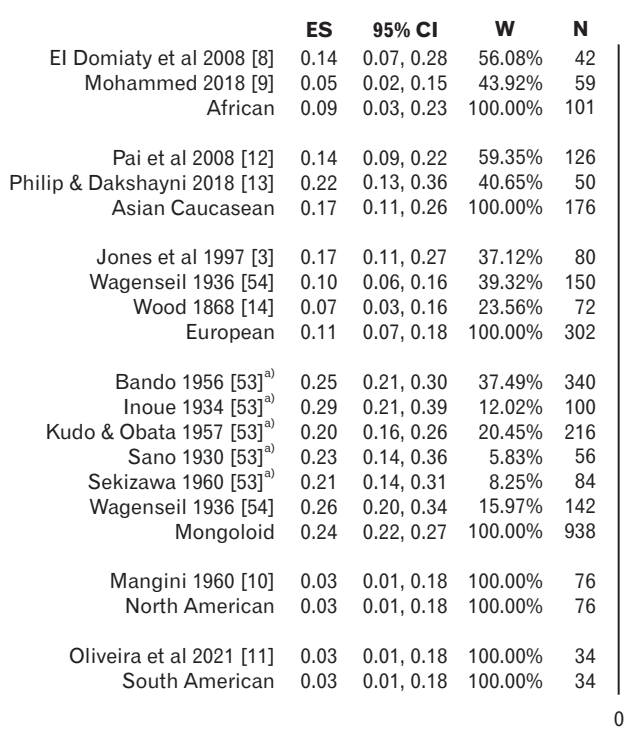

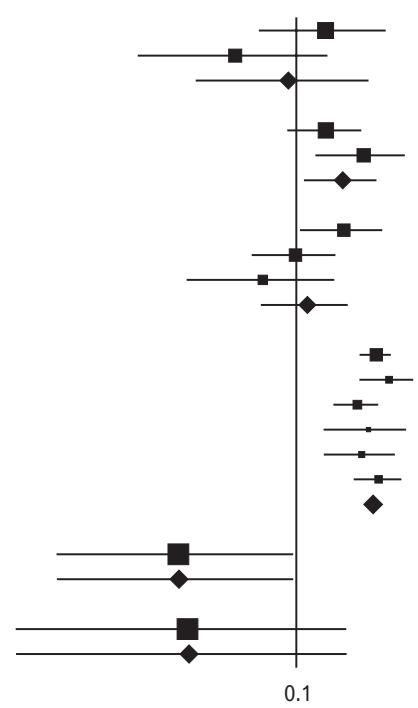

Fig. 3. Pooled weighted prevalence of accessory head of flexor digitorum profundus variant. ES, effect size (log-odds ratio); $\mathrm{CI}$, confidence interval; $\mathrm{W}$, weight of study (inverse variance); $\mathrm{N}$, sample size. ${ }^{\text {a) }}$ Secondary reference was used because the data collected from secondary reference due to inaccessibility of original manuscript.
Table 2. Characteristics of variants of Gantzer's muscle: laterality, sex, anatomical and morphological distribution

\begin{tabular}{|c|c|c|c|c|}
\hline \multirow{2}{*}{ Characteristic } & \multicolumn{2}{|c|}{ ahFPL } & \multicolumn{2}{|c|}{ ahFDP } \\
\hline & $\mathrm{P}(\%)$ & $95 \%$ CI (\%) & $\mathrm{P}(\%)$ & $95 \%$ CI (\%) \\
\hline \multicolumn{5}{|l|}{ Laterality } \\
\hline Right & 49 & $46-53$ & 9 & $5-14$ \\
\hline Left & 45 & $42-49$ & 10 & $6-15$ \\
\hline Unilateral & 47 & $43-51$ & 8 & $4-16$ \\
\hline Bilateral & 53 & $49-57$ & 10 & $6-16$ \\
\hline \multicolumn{5}{|l|}{ Sex } \\
\hline Male & 38 & $32-44$ & 12 & $7-18$ \\
\hline Female & 13 & $8-18$ & 23 & $14-36$ \\
\hline \multicolumn{5}{|l|}{ Origin } \\
\hline Flexor digitorum superficialis & 15 & $13-17$ & 74 & $65-82$ \\
\hline $\mathrm{CP}$ & 24 & $22-26$ & 6 & $3-13$ \\
\hline ME & 37 & $35-40$ & 15 & $9-23$ \\
\hline Antebrachial fascia & 4 & $3-5$ & NA & NA \\
\hline Dual origin (CP \& ME) & 8 & $7-10$ & NA & NA \\
\hline Pronator teres & NA & NA & 4 & $2-10$ \\
\hline \multicolumn{5}{|l|}{ Innervation } \\
\hline Anterior interosseous nerve & 66.7 & $64.1-69.3$ & 55.6 & $46-65$ \\
\hline Median nerve & 33.2 & $30.6-35.9$ & 44.4 & $36-55$ \\
\hline Ulnar nerve & 0.1 & $0.1-0.2$ & NA & NA \\
\hline \multicolumn{5}{|l|}{ Morphology } \\
\hline Fusiform & 72 & $69-75$ & NA & NA \\
\hline Voluminous & 2 & $1-4$ & NA & NA \\
\hline Slender & 10 & $8-13$ & NA & NA \\
\hline Voluminous \& fusiform & 1 & $0-1$ & NA & NA \\
\hline Triangular & 5 & $3-6$ & NA & NA \\
\hline Strap-like & 4 & $3-6$ & NA & NA \\
\hline Papillary like & 6 & $4-8$ & NA & NA \\
\hline
\end{tabular}

ahFPL, accessory head of flexor pollicis longus; ahFDP, accessory head of flexor digitorum profundus; $\mathrm{P}$, prevalence; $\mathrm{CI}$, confidence interval; $\mathrm{CP}$, coronoid process of ulna; ME, medial epicondyle of humerus; NA, not applicable. spectively. The pooled prevalence that varied in the cumulative analysis was $4 \%$ (48\% to $52 \%$ ). The overall heterogeneity was $89 \%$, which was much lower than earlier meta-analysis. The African, Mongoloid, and North American ethnicities had a higher prevalence than other ethnic groups for ahFPL. It was more frequent on the right side. ME was the commonest site of origin for ahFPL, and the muscle belly of FPL was the most common site of its insertion.

Similarly, the fascial sheath of FDS was the commonest site of origin, and FDP tendon for the index finger was the commonest insertion site for ahFDP. AIN predominantly innervated both variants. The fusiform shape was most frequent in both variants.

The ahFPL is a wide variation in modern humans, and it has clinical significance, especially in AIN and median nerve compression. For example, the Gantzer's muscle, or ahFPL, which acts as an additional head of the FPL, would enhance thumb flexion, indicating a functional difference from other primates [12]. Similarly, authors speculate that ahFDP might be improving pinching action or flexion of other fingers.

\section{Agreement or disagreement with other studies}

The prevalence of Gantzer's muscle has been shown to be $44.2 \%$, with a $95 \%$ confidence interval of $34.7 \%$ to $54 \%$ in a previous meta-analysis conducted by Roy et al. (2015) [6]. The authors have computed only the prevalence of the ahFPL variant in 2,358 upper limbs. We considered both variants for pooled estimation. The prevalence of ahFPL in the present meta-analysis was $48 \%$ (95\% CI, 44\%-52\%) in 5,903 upper limbs. The difference in prevalence between both meta- 
Table 3. Characteristics of variants of Gantzer's muscle: insertion of both variants

\begin{tabular}{|c|c|c|c|c|c|}
\hline \multicolumn{3}{|c|}{ ahFPL } & \multicolumn{3}{|c|}{ ahFDP } \\
\hline Insertion & $\mathrm{P}(\%)$ & 95\% CI (\%) & Insertion & $\mathrm{P}(\%)$ & $95 \% \mathrm{CI}(\%)$ \\
\hline Muscle & 61 & $52-70$ & Index finger tendon & 47 & $37-57$ \\
\hline Tendon & 13 & $7-20$ & Middle tendon & 20 & $13-29$ \\
\hline Proximal third of forearm & 71 & $66-76$ & Ring finger tendon & 0 & $0-7$ \\
\hline Middle third of forearm & 23 & $18-27$ & Little finger tendon & 10 & $5-18$ \\
\hline \multirow[t]{2}{*}{ Lower third of forearm } & 6 & $3-8$ & Middle \& ring finger tendon & 20 & $13-29$ \\
\hline & & & Middle, ring \& little finger tendon & 3 & $1-9$ \\
\hline
\end{tabular}

ahFPL, accessory head of flexor pollicis longus; ahFDP, accessory head of flexor digitorum profundus; $\mathrm{P}$, prevalence; CI, confidence interval.

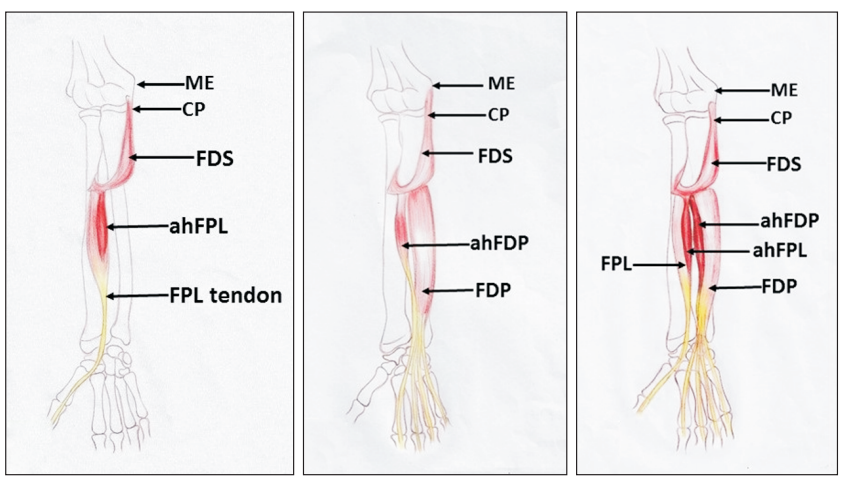

Fig. 4. Classification of Gantzer's muscle. ME, medial epicondyle of humerus; CP, coronoid process of ulna; FDS, flexor digitorum superficialis; ahFPL, accessory head of flexor pollicis longus; ahFDP, accessory head of flexor digitorum profundus.

analyses is attributed to higher sample size. The present meta-analysis examined more than double the sample size of the previous meta-analysis. The authors $[3,12,37,53]$ reported Gantzer's muscle prevalence, which varied from $60 \%$ to $71 \%$. These authors reported both variants. The studies [14, $15,25,28,38,41,47$ ] reported lower prevalence (39\%-55\%) and they only included ahFPL variant. The second variant, i.e., ahFDP, might have been missed due to ignorance. Such ignorance may be dealt with in the classification of these variants. The variants of Gantzer's muscle may be classified as per its morphology and attachment (Fig. 4). They were classified into three types. The suggested classification is as follows, based on the review of various literatures, which could be helpful in the future to study the relationship with the nearby structure.

Type I: ahFPL

Type Ia: Insertion into the belly of FPL

Type Ib: Insertion into the tendon of FPL

Type II: ahFDP

Type IIa: Insertion into the first tendon of FDP (index finger)

Type IIb: Insertion into the second tendon of FDP (middle finger)

Type IIc: Insertion into the third tendon of FDP (ring finger)

Type IId: Insertion into the fourth tendon of FDP (little finger)

Combination of any of two or more may be denoted as IIbcd or IIab, etc.

Type III: ahFPL and ahFDP

The sub-category of type III will be developed in the future with the availability of adequate data.

Type III is rare, and this subtype was not included for the pooled prevalence of variants of Gantzer's muscle due to inadequate description and data. The forearm muscle blastema develops from Interzone blastema over cartilage of developing radius and ulna at the 4 th week of intrauterine life $[6,8]$. The superficial muscle blastema migrates earlier than the blastema of the deeper muscle. FDS, FDP, and FPL are phylogenetically newer muscles that develop from volar hand blastema, and they ascend upwards to reach the definitive origin [12]. The fascial sheath of superficial muscles like FDS or pronator teres a guide for deeper FPL and FDP. The variants of Gantzer's muscle might be developmental errors [3, 12]. The FPL is the newer muscle (phylogenetically) among the forearm flexors, which could be the reason for the higher prevalence of ahFPL.

\section{Clinical implications}

These muscles generally lie deep to $\mathrm{MN}$ and are innervated by AIN [56]. The Gantzer's muscle has long been debated as a cause of neurological compression of AIN or MN. Tabib et al. [57] documented AIN syndrome caused by Gantzer's muscle. The patient had isolated weakness of the FPL and was unable to pinch between thumb and index finger. The pronated and extended elbow may cause characteristic pain in front of the mid-forearm. Electrodiagnostic investigation revealed moderate slowing of conduction velocity. On surgical exploration, Gantzer's muscle along with swollen AIN. 
The surgical removal led to the resolution of pain within a month. Similar reports were also noted in many other literatures [57-60]. Such syndrome was named as Kiloh-Nevin syndrome or AIN syndrome. This disorder also often leads to loss of pinching $[12,56]$.

\section{Limitation \& potential bias}

The high heterogeneity of pooled prevalence and inadequate data of sex distribution were the significant limitations. The high heterogeneity was mainly attributed to the variable population of studies. Most old studies lack sexbased data, and retrieving such data from the author's communication was impossible. It is the scope of further research. The strength of the current meta-analysis is that the present study has a double sample size than the previous one.

\section{Conclusion}

The prevalence of Gantzer's muscle is 65\%. It has two major variants: ahFPL and ahFDP. Both variants have population and sex variations. The origin of both variants is almost similar, but their insertions vary. Accessory head of FPL inserts on belly or tendon of FPL. Still, the other variant (ahFDP) inserts on the tendon of the FDP for the index and middle finger.

\section{ORCID}

Adil Asghar: https://orcid.org/0000-0002-1404-1298

Rakesh Kumar Jha:

https://orcid.org/0000-0003-1292-5927

Apurba Patra: https://orcid.org/0000-0002-1107-4481

Binita Chaudhary: https://orcid.org/0000-0002-1922-7630

Brijendra Singh: https://orcid.org/0000-0002-3501-0896

\section{Author Contributions}

Conceptualization: AA, RKJ. Data acquisition: AA, RKJ, BC. Data analysis or interpretation: AA, AP. Drafting of the manuscript: AA, RKJ, BC. Critical revision of the manuscript: AP, BC. Approval of the final version of the manuscript: all authors.

\section{Conflicts of Interest}

No potential conflict of interest relevant to this article was reported.

\section{References}

1. Zdilla MJ, Pacurari P, Celuck TJ, Andrews RC, Lambert HW. A Gantzer muscle arising from the brachialis and flexor digitorum superficialis: embryological considerations and implications for median nerve entrapment. Anat Sci Int 2019;94:150-3.

2. Gantzer KFL. [Dissertation on the anatomical variations of the muscular structure: with the consent of the highly esteemed medical class chaired by Charles Asmund Rudolph]. Berolini: Typis Joannis Friderici Starckii; 1813. Latin.

3. Jones M, Abrahams PH, Sañudo JR, Campillo M. Incidence and morphology of accessory heads of flexor pollicis longus and flexor digitorum profundus (Gantzer's muscles). J Anat 1997;191(Pt 3):451-5.

4. Yang K, Jung SJ, Lee H, Choi IJ, Lee JH. Topographical relations between the Gantzer's muscle and neurovascular structures. Surg Radiol Anat 2017;39:843-8.

5. Gyambibi A, Lemelin P. Comparative and quantitative myology of the forearm and hand of prosimian primates. Anat Rec (Hoboken) 2013;296:1196-206.

6. Roy J, Henry BM, Pękala PA, Vikse J, Ramakrishnan PK, Walocha JA, Tomaszewski KA. The prevalence and anatomical characteristics of the accessory head of the flexor pollicis longus muscle: a meta-analysis. PeerJ 2015;3:e1255.

7. Henry BM, Tomaszewski KA, Ramakrishnan PK, Roy J, Vikse J, Loukas M, Tubbs RS, Walocha JA. Development of the anatomical quality assessment (AQUA) tool for the quality assessment of anatomical studies included in meta-analyses and systematic reviews. Clin Anat 2017;30:6-13.

8. El Domiaty MA, Zoair MM, Sheta AA. The prevalence of accessory heads of the flexor pollicis longus and the flexor digitorum profundus muscles in Egyptians and their relations to median and anterior interosseous nerves. Folia Morphol (Warsz) 2008;67:63-71.

9. Mohammed WHE. Prevalence and morphology of Gantzer's muscle: a cadaveric based study [theses]. Omdurman: Omdurman Islamic University; 2018.

10. Mangini U. Flexor pollicis lungus muscle. Its morphology and clinical significance. J Bone Joint Surg Am 1960;42:467-70.

11. Oliveira KM, Breder CB, Ponte EF, Cordeiro AF, Oliveira MFS, Gomes WAPR, Gonçalves MF, Gonçalves GR, Grecco LH, Meggiolaro EDA, Silva JGBPCP, López CAC. The accessory heads of the muscles flexor pollicis longus and flexor digitorum profundus (Gantzer muscle) - an anatomical study in Brazilian cadavers. Morphologie 2021 Mar 17 [Epub]. https://doi. org/10.1016/j.morpho.2021.02.010.

12. Pai MM, Nayak SR, Krishnamurthy A, Vadgaonkar R, Prabhu LV, Ranade AV, Janardhan JP, Rai R. The accessory heads of flexor pollicis longus and flexor digitorum profundus: incidence and morphology. Clin Anat 2008;21:252-8.

13. Philip SE, Dakshayani KR. A morphological study of a rare 
variant of Gantzer's muscle. Int J Anat Res 2018;6:4811-4.

14. Wood J. XVII. Variations in human myology observed during the winter session of 1867-68 at King's College, London. Proc Royal Soc London 1868;16:483-525.

15. al-Qattan MM. Gantzer's muscle. An anatomical study of the accessory head of the flexor pollicis longus muscle. J Hand Surg Br 1996;21:269-70.

16. Bagoji IB, Doshi MA, Hadimani GA, Bannur BM, Patil BG, Patil BS, Das KK. Incidence and morphology of the accessory head of the flexor pollicis longus muscle (Gantzer's muscle) in South Indian population. J Anat Soc India 2017;66(Suppl 1):S50.

17. Bajpe R, Tarakeshwari R, Shubha R. Gantzer muscles; a study on 50 cadaveric upper limbs. Nat J Clin Anat 2015;4:179-85.

18. Afroze MKH, Umesh SN, Sangeeta M, Varalakshmi KL, Tiwari S. An anatomical and morphological study on accessory head of flexor pollicis longus (Gantzer's muscles) and its clinical emphasis. Int J Anat Res 2020;8:7568-71.

19. Ballesteros DR, Forero PL, Ballesteros LE. Accessory head of the flexor pollicis longus muscle: anatomical study and clinical significance. Folia Morphol (Warsz) 2019;78:394-400.

20. Bangarayya V, Narayana P, Pillai T, Priyanka K. A study on accessory muscle of flexor compartment of forearm. IOSR J Dent Med Sci 2018;17:18-21.

21. Bilecenoglu B, Uz A, Karalezli N. Possible anatomic structures causing entrapment neuropathies of the median nerve: an anatomic study. Acta Orthop Belg 2005;71:169-76.

22. Burute P, Vatsalaswamy P. Accessory heads of forearm flexors and flexor carpi radialis brevis: a cadaveric study with clinical significance. Int J Anat Res 2017;5:3698-703.

23. Caetano EB, Sabongi JJ, Vieira LÂ, Caetano MF, Moraes DV. Gantzer muscle. An anatomical study. Acta Ortop Bras 2015;23:72-5.

24. Chakravarthi KK, Ks S, Venumadhav N, Sharma A, Kumar $\mathrm{N}$. Anatomical variations of brachial artery - its morphology, embryogenesis and clinical implications. J Clin Diagn Res 2014;8:AC17-20.

25. Dellon AL, Mackinnon SE. Musculoaponeurotic variations along the course of the median nerve in the proximal forearm. J Hand Surg Br 1987;12:359-63.

26. Desai RR, Desai AR, Ambali MP. Incidence of accessory head of flexor pollicis longus (only in males) and its clinical significance. Nat J Integr Res Med 2017;8:88-91.

27. Dolderer JH, Prandl EC, Kehrer A, Beham A, Schaller HE, Briggs C, Kelly JL. Solitary paralysis of the flexor pollicis longus muscle after minimally invasive elbow procedures: anatomical and clinical study of the anterior interosseous nerve. Plast Reconstr Surg 2011;127:1229-36.

28. Dykes J, Anson BJ. The accessory tendon of the flexor pollicis longus muscle. Anat Rec 1944;90:83-7.

29. Gunnal S, Siddiqui A, Daimi S, Farooqui M, Wabale R. A study on the accessory head of the flexor pollicis longus muscle (Gantzer's muscle). J Clin Diagn Res 2013;7:418-21.

30. Hemmady MV, Subramanya AV, Mehta IM. Occasional head of flexor pollicis longus muscle: a study of its morphology and clinical significance. J Postgrad Med 1993;39:14-6.

31. Herrold CB, Cook RL, Burkett JT, Hobeika NA, Zdilla MJ, Lambert HW. The Gantzer muscle: an expanded study of this variant forearm muscle. FASEB J 2020;34:1-1.

32. Kara A, Elvan O, Yildiz S, Ozturk H. Accessory head of flexor pollicis longus muscle in fetuses and adult cadavers and its relation to anterior interosseous nerve. Clin Anat 2012;25:601-8.

33. Khade B, Chaudhari G, Yadav N, Mangalgiri A. Anatomical study of accessory head of flexor pollicis longus and its clinical significance. Natl J Clin Anat 2020;9:151-4.

34. Kida M. [The morphology of Gantzer's muscle, with special reference to the morphogenesis of the flexor digitorum superficialis]. Kaibogaku Zasshi 1988;63:539-46. Japanese.

35. Kumari A, Kumar S, Akhtar MJ, Ratnesh R, Kumar V. Morphological study of accessory heads of deep flexor muscle of forearm. J Med Sci Clin Res 2017;5:24172-6.

36. Le Double AF, Berry RJA. [Treatise on variations of the muscular system of man: and their significance from the point of view of zoological anthropology]. Paris: Schleicher frères; 1897. French.

37. Mahakkanukrauh P, Surin P, Ongkana N, Sethadavit M, Vaidhayakarn P. Prevalence of accessory head of flexor pollicis longus muscle and its relation to anterior interosseous nerve in Thai population. Clin Anat 2004;17:631-5.

38. Malhotra VK, Sing NP, Tewari SP. The accessory head of the flexor pollicis longus muscle and its nerve supply. Anat Anz 1982;151:503-5.

39. Matsunaga K, Matsuzaki A, Miyauchi R. Relationship of Gantzer's muscle (accessory head of flexor pollicis longus) with median and anterior interosseous nerves. Orthop Traumatol 2000;49:845-9.

40. Mustafa AYAE, Alkushi AG, Alasmari WAM, Ali Sakran AME, Elamin AM. Anatomical study of theaccessory heads of the deep flexor muscles of theforearm (Gantzer muscles). Int J Anat Res 2016;4:2984-7.

41. Mori M. Statistics on the musculature of the Japanese. Okajimas Folia Anat Jpn 1964;40:195-300.

42. Ravi Prasanna KH, Das AK, Kulkarni AL. Study of morphology of Gantzer muscle in forearm and its clinical significance. Sch Int J Anat Physiol 2019;2:261-4.

43. Riveros A, Olave E, Sousa-Rodrigues C. Anatomical study of the accessory head of the flexor pollicis longus muscle and its relationship to the anterior interosseous nerve in Brazilian individuals. Int J Morphol 2015;33:31-5.

44. Sato S. Statistical studies on the anomalous muscles of the Kyushu-Japanese. 4. The muscles of the upper limb. Kurume Med J 1969;16:69-81.

45. Sharma M, Chabbra U, Kaushal S, Patnaik VVG, Prashar R. Accessory head of flexor pollicis longus muscle. J Exerc Sci Physiother 2008;4:15-8.

46. Shayo J, Pokhojaev A, Medlej B. The Gantzer's muscle: an anatomical and US study [Internet]. Princeton, NJ: Labome. Org-Research; 2015 [cited 2021 May 27]. Available from: http:// www.labome.org/research/The-Gantzer-s-muscle-an-anatom- 
ical-and-US-study.html.

47. Shirali S, Hanson M, Branovacki G, Gonzalez M. The flexor pollicis longus and its relation to the anterior and posterior interosseous nerves. J Hand Surg Br 1998;23:170-2.

48. Tamang BK, Sinha P, Sarda RK, Shilal P, Murlimanju BV. Incidence and morphology of accessory head of Flexor pollicis longus muscle--an anatomical study. J Evol Med Dent Sci 2013;2:6800.

49. Tubbs RS, Custis JW, Salter EG, Wellons JC 3rd, Blount JP, Oakes WJ. Quantitation of and superficial surgical landmarks for the anterior interosseous nerve. J Neurosurg 2006;104:78791.

50. Uyaroglu FG, Kayalioglu G, Erturk M. Incidence and morphology of the accessory head of the flexor pollicis longus muscle (Gantzer's muscle) in a Turkish population. Neurosciences (Riyadh) 2006;11:171-4.

51. Oh CS, Chung IH, Koh KS. Anatomical study of the accessory head of the flexor pollicis longus and the anterior interosseous nerve in Asians. Clin Anat 2000;13:434-8.

52. Yu JM, Yoon SP, Kim J. Accessory head of flexor pollicis longus in Jeju islander cadavers. J Med Life Sci 2018;15:16-8.

53. Tomizawa I. Arthropological studies on variation of the mus- cles of upper extremity of the Ainu. Sapporo Med J 1986;55:10123.

54. Wagenseil F. [Investigations into the musculature of the Chinese]. Z Für Morphol Anthropol 1936;36:39-150. German.

55. Dubois de Mont-Marin G, Laulan J, Le Nen D, Bacle G. Topographic anatomy of structures liable to compress the median nerve at the elbow and proximal forearm. Orthop Traumatol Surg Res 2021;107:102813.

56. Ciftçığlu E, Kopuz C, Corumlu U, Demır MT. Accessory muscle in the forearm: a clinical and embryological approach. Anat Cell Biol 2011;44:160-3.

57. Tabib W, Aboufarah F, Asselineau A. [Compression of the anterior interosseous nerve by Gantzer's muscle]. Chir Main 2001;20:241-6. French.

58. Degreef I, De Smet L. Anterior interosseous nerve paralysis due to Gantzer's muscle. Acta Orthop Belg 2004;70:482-4.

59. Nakano KK, Lundergran C, Okihiro MM. Anterior interosseous nerve syndromes. Diagnostic methods and alternative treatments. Arch Neurol 1977;34:477-80.

60. Rodner CM, Tinsley BA, O'Malley MP. Pronator syndrome and anterior interosseous nerve syndrome. J Am Acad Orthop Surg 2013;21:268-75. 